\title{
2014 APSA Teaching and Learning Conference and Track Summaries
}

\author{
Kimberly A. Mealy, Director, APSA Education, Professional, and Diversity Programs
}

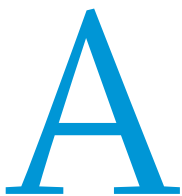

PSA held the 11th annual APSA Teaching and Learning Conference February 7-9, 2014, in Philadelphia, Pennsylvania. The 2014 program committee, chaired by Victor Asal (SUNY, University of Albany) issued the following theme for this year's meeting: "Teaching Inclusively: Integrating Multiple Approaches into the Curriculum." Meeting highlights included APSA executive director Steven Rathgeb Smith's keynote address and a dynamic preconference short course on massive open online courses (MOOCs).

\section{MEETING FORMAT}

The APSA Teaching and Learning Conference uses the working group format, which encourages small working groups of scholars to engage in intensive and sustained discussions of original research on pedagogical topics and the scholarship of teaching and learning (SOTL) in political science. Each working group or track is organized around a special theme. To facilitate the discussions, all meeting participants attend one working group for the duration of the meeting. The conference also features special interactive workshops that focus on practical issues related to teaching.

\section{CONFERENCE OVERVIEW}

The 2014 APSA Teaching and Learning Conference featured 14 moderated tracks organized around themes such as civic engagement; diversity, inclusiveness and equality; integrating technology into the classroom; internationalizing the curriculum, and program assessment. A new track on distance learning was offered this year, as well as a number of workshops addressing various themes related to simulations and role play, learning communities, active learning, and publishing in SOTL.

More than 300 individuals-including 39 graduate students-from a variety of academic and nonacademic institutions participated in the 2014 conference. Meeting participants enjoyed a number of plenary sessions. During the opening session, John Aldrich (APSA President) and Kimberly Mealy (APSA Director of Education, Professional, and Diversity Programs) provided welcoming remarks. Steven Rathgeb Smith (APSA Executive Director) presented the Pi Sigma Alpha Keynote Address titled "Teaching Political Science: Innovation, Change, and the Role of the Association." John Ishiyama (University of North Texas) and Chad Raymond (Salve Regina University) cofacilitated the preconference short course "A Conversation on the Advantages and Disadvantages of MOOCs (Massive Open Online Courses) in Political Science and Civic Education." The meeting also featured a memorial tribute to the late Craig Brians (Virginia Tech), a long-time leader in the political science teaching and learning community, organized by the APSA Teaching and Learning Conference program committee, the APSA Organized Section on Political Science Education, and the APSA Committee on Teaching and Learning. The meeting concluded on February 9, 2014 with a plenary session in which the participants and track moderators shared highlights and take-away points from each track, followed by recommendations for the future of political science education.

\section{POSTCONFERENCE DETAILS}

Materials and resources from the Teaching and Learning Conference are publically available. To download papers and to view video clips keynote and the short course on MOOCs, visit www. apsanet.org/teachingconference.

\section{PROGRAM COMMITTEE}

APSA thanks the following individuals who served on the program committee and as track moderators.

\author{
Victor Asal (Chair), SUNY, University at Albany \\ Mark Johnson, Minnesota State Community and Technical College \\ Agnieszka Paczynska, George Mason University \\ Boris Ricks, California State University, Northridge \\ Cameron Thies, Arizona State University \\ Sherri Wallace, University of Louisville
}

We would also like to thank the 2014 meeting attendees and the APSA staff for contributing to success of the meeting. We look forward to seeing you at the 2015 meeting.

\section{TRACK SUMMARIES}

Track summaries from the 2014 APSA Teaching and Learning Conference are published in the following pages of $P S$. These summaries include highlights and themes that emerged from the research presented in each track. The summary authors also issued recommendations for faculty, departments, and the discipline as a whole-providing suggestions for new strategies, resources, and approaches aimed at advancing political science education throughout the discipline and beyond. In keeping with the theme of the meeting, "Teaching Inclusively: Integrating Multiple Approaches into the Curriculum," there are common themes that emerged throughout the track summaries and the recommendations contained therein. For example: (1) The call for increased appreciation and use of a diverse set of research methods, technologies, and teaching platforms acknowledges that not only do political issues and problems require unique research methods, but students in the same class may also have unique problem-solving and learning skills. Therefore faculty may need to incorporate a variety of pedagogical approaches. (2) Increased collaboration, across the discipline and departments, is needed to share examples of graduate program curricula, assessment resources, simulation exercises, and innovations for incorporating theories of diversity in the curriculum with fellow teachers and political science facultyespecially community college instructors. (3) Finally, increase focus on collecting good examples of teaching, learning, and research successes so that individuals, and the discipline, can effectively advocate on behalf of political science education. These are but a few examples of the meaningful discourse and ideas that emanated from the 2014 track presentations and discussions. 
The fourteen tracks are listed here and the track summaries for each are featured below:

- Civic Engagement

- Conflict and Conflict Resolution

- Core Curriculum/General Education

- Curricular and Program Assessment

- Distance Learning

- Diversity, Inclusiveness, and Equality

- Graduate Education:Teaching and Advising Graduate Students

- Integrating Technology into the Classroom

- Internationalizing the Curriculum

- Simulations and Role Play I: International and Domestic Politics and Their Intersection

- Simulations and Role Play II: Assessment and Methodology

- Teaching and Learning at Community Colleges

- Teaching Political Theory and Theories

- Teaching Research Methods

\section{CIVIC ENGAGEMENT}

Elizabeth Bennion, Indiana University, South Bend

Kathleen Cole, Metropolitan State University

Bobbi Gentry, Bridgewater College

The papers presented at this year's track on civic engagement demonstrate the continuing significance of civic engagement pedagogies for teaching and learning in political science. These papers build on the excellent scholarship presented in APSA's recent publication, Teaching Civic Engagement, while identifying new areas for future theorizing and research. During this year's track, participants sought to identify ways to overcome challenges and achieve desired learning outcomes through the pedagogy of civic engagement. As we continue to develop the scholarship and practice of civic engagement pedagogies, we suggest some considerations that should inform the study of teaching and learning in political science.

\section{Overcoming challenges}

Civic engagement pedagogy continues to be used to enhance the knowledge, skills, and civic identities of our students. Civic engagement engages students in academic inquiry within the community. Instructors seeking to use civic engagement as an approach to teaching have faced several challenges in the past, including defining civic engagement, obtaining faculty and administrative buy-in, and building community relations. These challenges continue to pose significant obstacles to instructors implementing civic engagement pedagogies throughout courses in the discipline.

Without a common definition of civic engagement, the development of a scholarly conversation around civic engagement pedagogies was stunted. However, McCartney's recent articulation of a potential definition for civic engagement may provide a useful foundation for research on theories and practices of civic engagement pedagogies. She explains civic engagement as:

a catch-all term that refers to an individual's activities, alone or as part of a group, that focus on developing knowledge about the community and its political system, identifying or seeking solutions to community problems, pursuing goals to benefit the community, and participating in constructive deliberation among community members about the community's political system and community issues, problems and solutions (McCartney 2013, 14).

Beginning from this common definition allows scholars of civic engagement a departure point for continuing to interrogate their conceptions of civic engagement while developing a more robust and lively debate about the purposes and best practices of civic engagement pedagogies.

Another obstacle to incorporating civic engagement activities in political science courses is the resistance from university administrators and colleagues in the discipline toward encouraging explicitly political activity among students. Some view civic engagement practices as potentially threatening to university interests or as political indoctrination. As a result, scholars of civic engagement must clearly communicate the goals and benefits of civic engagement education to skeptical audiences.

Finally, participants identified developing collaborative and mutually beneficial relationships between university students and community groups as an ongoing struggle. Participants agreed that civic engagement activities should be animated by a sense of equality among the participants (both students and community members) and guided by the needs and preferences of the community. Activities should not put students in the position of "experts." Community members must be seen as co-contributors in the development of new knowledge and skills. However, achieving these goals remains a challenge and will continue in the future. Developing the reciprocal relationships favored by scholars of community engagement requires ongoing attention to power dynamics between participant groups.

\section{Promoting learning through engagement}

There are a myriad of ways to engage students in civic life. Presenters in this track highlighted the diversity of approaches to civic education and documented positive learning outcomes from a variety of engaged approaches. Students who engage in structured, deliberative consensus building say that they are more likely to participate in community problem solving in the future (Burlingame and Strachan). Civic engagement can also occur through programming, including Constitution Day events that engage local school children in discussions about the ideals set forth in the Constitution (Smith, Miracle, Anderson 2014), or projects that bridge theory and practice through campus-based voter education drives and partnerships with community high schools that engage local students in a robust dialogue about democratic citizenship and community problem solving (Matto and Murphy). Students engage in their communities by talking with children of immigrants about their hope and fears and the ways in which they define membership-and develop a sense of belonging-in multiple, overlapping communities (Commins). Students can also serve the public by conducting background research, operating cameras, and screening calls as part of a live weekly television show featuring political leaders (Bennion). Students gain practical research skills they can use throughout their lives to help themselves and others by requesting information using the Freedom of Information Act (Le and Bass). Students, including those in large courses, can also get a global perspective with project based learning requiring formal policy briefs (Feeley). All of these projects, whose details are available through APSA Connect, offer students new knowledge and skills, while fostering a civic identity among students that is predicted to shape future behavior. 
Civic engagement as high impact pedagogy

Civic engagement changes our classroom environment from a "sage on the stage" model to a "guide on the side." In addition to goals and objectives, we encourage our students to think about the process that includes struggles, success, and stagnation. We want our students to move from passive observers to active citizens who know how to navigate the institutions, processes, and human elements of politics. Pedagogically, civic engagement can be a rewarding experience for students, faculty, and community members. Faculty new to this approach can develop a small-scale project for the classroom and develop the scope of the project in subsequent semesters (Forestiere). Forestiere, for example, developed a small project involving student-resident interviews at a local nursing home that has now become the focus of semester-long exploration of quantitative and qualitative methods and the basis of a forthcoming textbook for methods instructors across the globe.

\section{The future of civic engagement in political science}

We need to move forward the profession and the scholarship of civic engagement in four major ways:

Feasibility: Practitioners of civic engagement pedagogy work to provide an interactive, valuable, and collaborative experience for their students. However, we acknowledge that these intensive experiences limit class size. With smaller class sizes, scholars of civic engagement are challenged by the need for quantitative data. More collaboration is needed across institutions to form a more complete cross-comparison analysis and larger sample sizes. We encourage the development and sustainability of a consortium of researchers of civic engagement to work together to support intercampus projects. Interested teacher-scholars can join the Consortium for Intercampus SoTL Research at http://is.gd/Consortium.

Acceptability: Civic engagement requires intensive faculty time and effort. To build a civic engagement project, faculty members need time, resources, and energy. However, because civic engagement is not included in many institutions' tenure and promotion guidelines, few junior faculty spend time developing civic engagement pedagogies. For the discipline, we need to encourage civic engagement pedagogies and research to be counted in the tenure and promotion process as innovative teaching and as scholarship that contributes to the field.

Visibility: Throughout the process of our civic engagement projects, we have to acknowledge that we have multiple constituenciesstudents, other faculty, administration, community members, accrediting agencies, donors, and other stakeholders (e.g., trustees and/or state legislators). As we continue to hone our assessments and best practices in civic engagement, we have to document the impact of our work and communicate this impact to these diverse audiences.

Sustainability: Civic engagement takes resources-money, time, and energy. To sustain the progress that we have already made, we need to push for higher education reform such as the suggestions made by the American Association of Colleges and Universities (AAC\&U) in their publication, A Crucible Moment, which encourages institutions to be centers for citizenship development and places where knowledge and skill development are appreciated. Change starts at the institutional level. Institutions can use civic engagement as a recruitment and retention tool given that two research-supported outcomes of high impact teaching practices are (1) increased retention rates and (2) increased feelings of belonging to a community.

\section{Conclusion}

Civic engagement practices and pedagogies seem especially necessary during this important political moment. Civic engagement pedagogies teach valuable political skills and encourage the cultivation of civic identities in our students. In this period of decline in the civic health of our democracy, now more than ever we need students with the skills and identities that civic engagement pedagogies encourage. In addition, civic engagement projects developed in reciprocal relationships with community members help us as political scientists communicate the value of our work to broader constituencies. When funding and support for social sciences is threatened, we need demonstrable benefits of our teaching and research. Thus, civic engagement practices and pedagogies should be viewed as critically important for both student learning and the health of our discipline.

\section{R E F E R E N C E}

McCartney, Alison Rios Millet. 2013. "Teaching Civic Engagement: Debates, Definitions, Benefits, and Challenges.” In Teaching Civic Engagement: From Student to Active Citizen, eds. Alison Rios Millet McCartney, Elizabeth A. Bennion, and Dick Simpson. State of the Profession Series. Washington, DC American Political Science Association.

\section{CONFLICT AND CONFLICT RESOLUTION}

\author{
Bidisha Biswas, Western Washington University \\ Patrick McNamara, University of Nebraska at Omaha \\ Christina Sciabarra, University of Arizona
}

Participants in the Conflict and Conflict Resolution track discussed a wide range of issues related to the challenges of teaching conflict theory and the practice of conflict resolution. With a mix of international scholars, tenured and nontenured faculty, and graduate students, the discussions were lively and focused on assessment methods, approaches to practical skills training, and new strategies for innovation.

\section{Contributions and overall themes}

The key themes that emerged from the track discussions were the inclusion of practical skills to increase student employability, the need for improved assessments to measure learning outcomes, and the importance of innovation in introducing students to conflict resolution theory. Participants agreed that addressing these issues was paramount to improving both undergraduate and graduate education.

Practical Skills: Throughout the sessions, the participants noted two realities of today's higher education: students must be able to write well to find employment and that writing is the most underdeveloped skill students bring to their college experience. There was wide agreement that both undergraduate and graduate students struggle with proper grammar and writing structure and that this skill is perhaps the most important for finding employment as well as successfully obtaining a secondary degree. Bidisha Biswas discussed the ways in which she incorporates her experience working as a Franklin Fellow with the US Department of State into her course material. She discussed various exercises in which students must read, summarize, and analyze media reports with a focus on succinctly conveying the background, analysis, and recommendations in two pages or less. These assignments force students to start thinking strategically about what is relevant and what is not 
when providing information for quick consumption. Moreover, this requires students to edit and revise their work multiple times, which forces them to think about and correct grammatical and structural errors. This presentation sparked a lively discussion of techniques to improve student writing, including peer reviewers, targeted reviewing (limiting comments to three main thematic points), and multiple draft submissions. Each track session included aspects of this issue as more and more students enter political science and conflict resolution expecting to graduate with tangible skills. The final take-away from the various discussions regarding employability and incorporating practical work into an academic program was the ability to use course work to build skills that are valuable in both academia and on the job market.

Assessment and Design: A consistent theme throughout the track meetings as well as the entire conference was the need to incorporate research design into the assessments used in class. The two presentations on the impact of the use of simulations to encourage learning served as the starting point for this discussion. Agnieszka Paczynska's presentation provided a preliminary report of the impact of a series of simulations used in George Mason University's conflict resolution program. Her results suggested that the simulations improve student learning, although the level of improvement remained a topic for discussion. Christina Sciabarra's presentation of her original simulation using real and artificial states sparked additional conversation regarding the purpose of in-class simulations and the assessments used to measure their impact. In perhaps the most contentious track discussion, there was disagreement as to the value of asking students their opinion as to whether they enjoyed the experience and felt they gained something from it. This issue was also raised after David Dreyer's presentation on the use of music in teaching foreign policy. The issue of assessment design was easily couched in the greater debate of qualitative versus quantitative approaches to research design. Some track participants argued that such opinions should matter. Others pointed out that using standard experimental design techniques would yield the best result. While the participants discussed various means of designing assessments, the conclusion was that incorporating research methodology into assessments is not only important for accurate reporting of activity effectiveness, but necessary for broader course and curriculum design. Although opinions are valuable and should not be discounted, generalizable data provides another view of the importance and/ or effectiveness of a particular teaching method or exercise and both should be incorporated.

Innovation: Although innovative course design is no doubt a common theme throughout the conference, each presentation in the conflict and conflict resolution track included a discussion of incorporating innovation and creative thinking into course design. In a panel discussion that focused on crossing cultures, Joy Samad discussed his use of classic political theory to teach students in Sulaymaniya, Iraq (Kurdistan Region) about the use of violence and authoritarian regimes. Patrick McNamara's presentation, in contrast, focused on the use of videoconferencing between US and Pakistani students to address misinformation and build crosscultural relationships. Both presentations demonstrated the value of using other cultures to teach various aspects of conflict and resolution theory. Similarly, Christi Bartman demonstrated the effectiveness of listening to and reenacting Supreme Court arguments and dialogues in teaching students about conflict resolution. The use of technology to improve student learning and engagement was consistently presented, although the means of assessing its impact remain works in progress. Steven Curtis' presentation on teaching diplomacy by taking students to embassies and allowing them to interact with diplomats and foreign service officers offered another approach to hands-on teaching. Again, the question of assessment arose as Curtis used surveys to gauge student satisfaction and learning, but the take-away point from his presentation was the value of getting students out of the classroom and into the real world. As service learning becomes more popular and students seek opportunities to develop their experiences and skill sets, incorporating these kinds of activities into course design seems a natural, yet challenging, progression.

\section{Summing Up}

The discussion concluded with participants noting four main takeaways from this track. First, conflict and conflict resolution are relatively new subfields of study and are interdisciplinary in nature. As such, this area of study calls for innovative classroom techniques to communicate issues and cases that are often very unfamiliar to students. Second, students need a theoretically grounded foundation that also gives them practical skills that will help them in their employability. Third, writing skills are an important area of focus. In particular, track participants would like to encourage students to develop the ability to synthesize and distill complex issues into concise papers and memos. This is also an important practical skill that prospective employers value. Finally, track participants want to further explore and develop ways of tracking learning outcomes over time to assess what students have gained from courses on conflict and conflict resolution.

\section{CORE CURRICULUM/GENERAL EDUCATION}

\section{Lilian A. Barria, Eastern Illinois University \\ Andreas Broscheid, James Madison University \\ Tyson D. King-Meadows, University of Maryland, Baltimore County \\ Melinda A. Mueller, Eastern Illinois University \\ Erin E. Richards, Cascadia Community College \\ Henrik M. Schatzinger, Ripon College}

Political science course offerings are often a part of an institution's core curriculum requirements, in many cases through an American government course. It is important for all of us to think about how political science contributes to and enhances the undergraduate general education curriculum for both majors and nonmajors to be effective advocates for political science as part of the university curriculum as well as to those outside academia. With 10 presentations and 28 discussants, the track identified citizenship education as a core contribution of political science to education in general and to preparing individuals, through content and skill development, to be valuable members of society.

Papers in this track focused on a diversity of topics, including moving beyond the discussion of content versus skills, horizontally integrating learning objectives and skill development into core curriculum course content, and assessing the impact of political science courses in developing knowledge and skills. We conclude this track overview with recommendations for colleagues, APSA, and policymakers. 


\section{Addressing the content versus skills debate}

The track participants noticed, with a sense of relief, that the discussion about the role of political science courses in the core curriculum had gone beyond the content versus skills debate. Different pedagogies are needed to address the different learning styles of students. Several papers supported the claim that students' skill development occurred through the engagement with rigorous content and vice versa. Schatzinger and Strickler (Ripon College), for example, proposed the development of diversity knowledge and skills through horizontal integration of diversity-related content into the entire range of course topics in an American government course. Chapman (Binghamton University) used an introductory writing course to introduce students to political concepts and processes as well as to restructure political science instruction. Central to his teaching is a recursive course structure in which fundamental assumptions about human behavior are linked to the critical analysis of political outcomes and the concomitant consequences. Richards (Cascadia Community College) and Gilmour (Midland College) focused on changes in knowledge and interest in politics among community college students as precursors to civic engagement. Their pre- and posttest analysis indicated that an American government course contributes to an increase in student knowledge, a slight increase in student interest, and no change in student ideology. Maloyed (University of Nebraska, Kearney) and Kasniunas (Goucher College), in separate papers, provided examples of courses that balanced content and skills through team-based learning and community-based learning. Maloyed presented a case study of an American government class engaging in a campus research and advocacy project, while Kasniunas discussed the challenges of developing team-based learning in American government.

\section{Horizontal integration}

As mentioned earlier, several papers also focused on strategies for horizontal integration of learning objectives, whether content or skills, into course design. Horizontal approaches to learning objectives identify links, methods, themes, or clusters and apply them throughout a course. Schatzinger and Strickler's case for horizontal integration of diversity content serves as an example. However, they point out that the adoption of diversity as a theme in an American government course is most effective if (1) the value of diversity content is identified at the institutional level as a learning objective and (2) diversity is then approached in the curriculum across disciplines through pedagogical conversations. Kasniunas and Broscheid (James Madison University), in separate papers, focused on unifying content throughout their courses by using team-based learning strategies, which emphasize the development of problem-solving and critical thinking skills through in-class student group activities. Broscheid proposes identifying the central disciplinary questions or skills to which individual activities throughout the semester are connected. Kasniunas addresses this issue by using lectures to provide content that serves as a basis for in-class activities.

\section{Assessment and civic learning}

Several papers either focused on assessment processes or included assessment-based data in their analyses. On the one hand, Reed and Smith (Northwest Missouri State University), who were concerned with the decline of reading skills, directly tested the impact of integrating Cengage's Aplia into the American government course. They found that the use of Aplia had a positive effect on student reading and performance, with some evidence that the application may contribute to higher levels of student engagement. On the other hand, Slocum-Shaffer (Shepherd University) discussed the opportunities and challenges of developing a capstone course for majors as part of the core curriculum. The course served as a valuable tool by enhancing assessment efforts as students completed departmental assessment instruments within the course.

\section{Political science and the core curriculum}

Civic knowledge and citizenship skills provided a clear focus for this year's track. Springer and Litton (University of Mary) discussed the challenges of teaching a university-wide required citizenship course as they analyzed the development of their core textbook for the course. They also evaluated the impact of having instructors and faculty from outside political science teaching this course. Education for citizenship and engagement is a longer-term process, taking place over the course of years or even decades. Furthermore, responsible citizenship can express itself in a variety of attitudes and behaviors that are not (easily) measurable in a standardized fashion, as Mueller and Barria (Eastern Illinois University) point out from student and faculty surveys. Their research examined how well an entire general education curriculum addressed responsible citizenship and concluded that the core curriculum may provide a foundation for knowledge, but may only offer limited opportunities for direct civic action and engagement. In addition, both sets of authors discussed the value of having political scientists involved in their respective institutions' curriculum decisions, especially those regarding citizenship.

\section{Moving forward: dialogue and advocacy}

Although participants agreed that the balance between content knowledge and skills is still a relevant issue, the focus on civic knowledge and citizenship provided a clear focus for this year's track. The track participants agreed that future APSA Teaching and Learning Conference core curriculum tracks should focus more specifically on the assessment of learning outcomes related to engagement and citizenship. We need to better explore how to develop, teach, and assess citizenship skills for majors and nonmajors in the core curriculum. We also need to examine the role political scientists play in influencing general education content at their respective institutions and advocating for the value of citizenship skills to stakeholders.

If we agree that our significant contribution to general education is citizenship, how do we explain that role to funding units, stakeholders, and policymakers? Track participants recommended that, given the diversity of teaching expectations and requirements across the country, APSA consider strategies to assist community colleges and public universities in advocating at the state level. The track also recommended creating more opportunities for dialogue among different types of institutions (e.g., community colleges and four-year public and private institutions) for greater curriculum coherence and a stronger advocacy voice. APSA can assist in collecting data from states as well as businesses about employment trends and business expectations related to the knowledge and skills that political science brings to the table. Because advocating to stakeholders will require valid, reliable assessment data, track participants also call on APSA to continue to assist institutions regarding best practices for assessment techniques and analysis for a full range of institutions. APSA's leadership on these issues will help to answer the call made by APSA president John Aldrich, at the conference's opening session, to expand advocacy and outreach. 


\section{CURRICULAR AND PROGRAM ASSESSMENT}

\section{Shane Nordyke, University of South Dakota \\ Candace Young, Truman State University}

Our view of assessment, and what it may offer us, has matured substantially during the past decade. We have moved from a position of "Assessment is coming, how can we get through it?" to one of "How can we seize the discourse and momentum of assessment to best benefit our programs and our students?" Slowly, we see departments learning to stop treating assessment as a purely administrative exercise and instead use assessment to demonstrate effectiveness in the most important aspects of our discipline. This change is reflected in the assessment research we see at the APSA Teaching and Learning Conference. Papers in this year's track document research that examines more complex outcomes like critical thinking, efficacy, and resiliency. We are also seeing more papers that are moving beyond the outcomes of a single course and including more systematic comparative studies of curriculum and student outcomes. Within the varied body of work that was presented, we found our discussions focused on three primary questions: How do we overcome the methodological challenges associated with effective assessment? How similar are our goals, objectives, and outcomes across the discipline and what does this mean for collaboration in assessment efforts? How can we design assessment processes so that these are most beneficial to our students, our departments, and our colleagues?

A persistent challenge in effectively assessing programs is overcoming the methodological challenges that are associated with measuring what really matters. When asked to list the most important learning outcomes for the political science student, faculty members often prioritize skills such as critical thinking, effective oral and written communication, appreciation for diversity, and the responsibilities of citizenship, as much as, if not more than, specific knowledge sets (Butler 2014). These outcomes or competencies often have been more difficult to assess than the acquisition of rote knowledge. However, several of our track presenters directly addressed these challenges by developing rubrics and assessment techniques to assess critical thinking, (Grussendorf 2014 ; Kropf, Szmer, and Whitaker 2104), resiliency (Lusk 2014), and student perceptions of democracy and the utility of social science (Kropf et al. 2014). We also discussed the methodological challenges inherent in evaluating single courses as experiments, or even multiple courses that still lack random assignment. Will students self-select into experimental course designs in a way that will bias assessment results? In facing this particular challenge, Kropf et al. used propensity matching between students in control and treatment sections of a course to overcome potential bias that might be introduced through nonrandom assignment.

Much of our discussion was also centered on our possible identity crisis within the discipline. How far have we really come since Wahlke (1991)? To what extent do our various departments and programs look uniform relative to other social sciences? Most of us working in the United States tend to think of our programs as quite heterogeneous, with different emphasis on subfields and different patterns of coordination with related disciplines such as history, criminal justice, and public administration. With so much variation, to what extent were standard expectations possible? Despite evidence of the effectiveness of Wahlke recommendations, these have not been widely adopted
(McClellan and Maurer 2014; Cammarano and Oglesby 2014). However, international scholars within the track saw programs in the United States as relatively similar, at least compared to the diversity within their own programs (Botero 2014; Groth 2014). Further, an evaluation of the outcomes of political science programs reveals greater consistency than did a study of curricula (Butler 2014; Kohler and Young 2014).

Finally, we still look for the best ways to ensure that our assessment efforts benefit our students, departments, and colleagues. Developing and implementing effective assessment processes takes a significant amount of faculty time and effort. Hence, it is important that departments invest in not only properly incentivizing the work (through appropriate credit for service, work releases, etc.) but also ensure that assessment results are fully utilized. Assessment can be a useful faculty development exercise. Effective assessment techniques, such as well-developed capstone courses, can also enable students to better articulate the added value of their educational experiences. Finally, departments should reap the full returns of the investment by using assessment results to strategically negotiate for needed resources, similar to the way professional programs often use accreditation efforts.

Looking forward, this track's discussions encourage the discipline, and APSA in particular, to move forward in efforts to identify strengths of political science and ways to provide evidence of its achievements (Kohler and Young, 2014). Such evidence may be quite useful in pushing back against increasing numbers of lines and salary dollars going to programs with specialized accreditation as well as politicians who question the discipline's contributions. These efforts could include establishing a working group to evaluate the feasibility of moving toward an accreditation process for political science programs.

\section{RE F E R E N C E S}

Botero, Santiago Leyva, Andres Preciado, Jose Fortou, and Laura Toro. 2014 "The Institutionalization of Political Science in Colombia: An Analysis of the Curricula." Presented at the annual APSA Teaching and Learning Conference, Philadelphia, PA, February 7-9.

Butler, Christopher K. 2014. "Comparing Curricula and Assessment Processes of B.A. Programs in Political Science." Presented at the annual APSA Teaching and Learning Conference, Philadelphia, PA, February 7-9.

Cammarano, Joseph, and Mark Oglesby. 2014. "Learning from High School Teachers: How Trends in High School Can Inform Political Science Education.” Presented at the annual APSA Teaching and Learning Conference, Philadelphia, PA, February 7-9.

Groth, Terrie R. 2014. "The Case for Competency-Based Teaching and Learning in Political Science." Presented at the annual APSA Teaching and Learning Conference, Philadelphia, PA, February 7-9.

Grussendorf, Jeannie. 2014. "Reflections on Foreign Policy: Enhancing Students' Critical Thinking Skills." Presented at the annual APSA Teaching and Learning Conference, Philadelphia, PA, February 7-9.

Kohler, Ryan and Candace C. Young. 2014. "Political Science Departments, Assessment, and Implications." Presented at the annual APSA Teaching and Learning Conference, Philadelphia, PA, February 7-9.

Kropf, Martha, John Szmer, and Beth Elise Whitaker. 2014. "Using Propensity Matching to Evaluate the Effectiveness of an American Politics Large-Cours Design." Presented at the annual APSA Teaching and Learning Conference, Philadelphia, PA, February 7-9.

Lusk, Adam. 2014. "Using Metacognition to Teach Resiliency in Introduction to Political Science." Presented at the annual APSA Teaching and Learning Conference, Philadelphia, PA, February $7-9$.

McClellan, E. Fletcher and Brianna Maurer. 2014. "After Wahlke: New Models for Organizing the Undergraduate Political Science Major and the Prospects for Reform."

Wahlke, John C. 1991. "Liberal Learning and the Political Science Major: A Report to the Profession." PS: Political Science and Politics 24 (1), 48-6o. 


\section{DISTANCE LEARNING}

\section{Nanette S. Levinson, American University \\ Tracy S. Harbin, Seminole State College}

This year, 2014, marks the inaugural year for the Distance Learning track at the APSA Teaching and Learning Conference. The inclusion of this track recognizes the increased scholarly activity and even media coverage devoted to distance learning as a field. Taken as a whole, the research presented in this track highlights the emergence of distance learning in all of its myriad formats including as a strategic component for students, faculty, staff, and especially higher education administrators both in the United States and globally (Allen and Seaman 2013). Numerous questions and findings emerged from the track papers and discussions; in addition, these papers and discussions served as a foundation for identifying research and action opportunities. These questions, findings, and opportunities can be grouped into six sections: three main themes, an additional two action items for APSA and the profession, and future research elements.

\section{Theme one: "researching the best of both worlds"}

Track findings and discussion called for recognizing the multidirectional flow of information and practice between traditional classroom face-to-face learning and online learning situations. Many scholars have written about adapting aspects of what works best in the traditional classroom to online learning. However, research in this track also examined the transfer of research findings from what works best in an online setting back to the traditional classroom. This integration and "best of both worlds" approach calls for additional research to document this rich, nuanced finding of innovative transfers from distance to in-person teaching and learning.

\section{Theme two: "identifying cross-cultural, cross-generational, and} cross-institutional aspects of distance learning"

Research that emerged in relation to this theme ranged from the impacts of generational learning styles and use of technology to the outcomes of cross-cultural and cross-institutional collaborations (Friedmann, Pasztor, and Kang 2014). The work in this arena as well as discussants' comments emphasized the importance of not overlooking these key variables and the need for additional, rigorous research. Particularly important in the discussion was documenting the impacts of contexts with a focus on examining different absorptive capacities and different obligations among, for example, online learning situations in community colleges (Yount and Cavaliere 2014) and those of online professional master's degree programs in private universities (Wagner 2014). The treatment of culture also extended to research on crafting "online learning/classroom cultures."

\section{Theme three: "delineating dimensions of distance learning"}

Research in this arena addressed a range of dimensions. Beginning with a discussion of the issues of effectiveness and online component duration (Stangl 2014), the research reported in the track covered a wide range of online learning formats and components. One innovative component was the inclusion of and discussion of an online service learning option (Yount and Cavaliere 2014). Another was the use of online scenarios and discussion boards to teach emergency management skills in asynchronous environments (Wukich, Frew, and Steinberg 2014).
Several papers addressed the online learning continuum from individual online courses to online degree programs and the presence or absence of distinctive online learning assessment and distinctive student evaluation of teaching approaches (Levinson 2014; Moats 2014). Track participants questioned the practice of automatically using the same student-evaluation-of-teaching form for online teaching situations as for traditional classrooms. Others analyzed institutional differences regarding incentives and rewards for online faculty members.

Additional research highlighted the emergence of massive, open, online courses (MOOCs) (Caputo 2014; Levinson 2014; Quirk 2014) and led to the track's vibrant comparative analysis of these findings. Political science has only seen a recent increase in MOOCs both in the United States and around the world, compared to other disciplines. A range of issues emerged from this recent research and especially the advent of not-for-profit and for-profit "partners" and their roles in implementing MOOCs and, indeed, in implementing online learning as a whole. This research thread underlines the need for additional work assessing the impacts, ethics, and challenges of such partnerships both in the short term and long term. Finally, this research thread and related track discussions led to the track's formulation of possible future research elements as well as two opportunities/calls to action for APSA, as noted below.

Opportunity one: "crafting virtual mentoring for distance learning" With a focus on using findings regarding best practices in distance learning and, at the same time, recognizing findings that detail the need for more know-how as well as show-how in distance learning, the track participants unanimously advocated the addition of a virtual mentoring program for APSA members engaged in distance learning teaching and/or research. Such a program could easily build on the existing APSA mentoring program and fill a distinctive need niche in our field. Track discussants and authors volunteered to participate in this endeavor.

Opportunity two: "offering MOOCs for public education, civic engagement, and civic literacy"

Discussion surrounding the track's research dealing with a range of MOOC matters led to a realization that while current MOOCs in our field are housed in university settings and have numerous unresolved issues, there is an important opportunity for APSA to consider designing and offering MOOCs focused on civic engagement, civic literacy, and public education-all amplifying APSA's mission and APSA's incipient yet growing expertise in distance learning. The track also recommends that APSA establish a working group on MOOCs and civic education.

\section{Future research elements}

In sum, there is a need to move from anecdotal to more rigorous research designs. Such research can yield models for ethical and effective collaborations surrounding online learning and teaching. Studies need to include administrators and external partners (where appropriate) as well as faculty, staff, and students. Prior research on public-private partnerships could serve as a foundation for this work. The various cultural contexts from the individual online culture to the cultures of participating students, faculty, institutions, and external partners also need to be systematically addressed. 
Finally, if APSA accepts the call for designing and offering MOOCs related to civic engagement both locally and globally, research components should be built in to track and assess such efforts and their critical success factors.

\section{R E F E R E N C E S}

Allen, I. Elaine, and Jeff Seaman. 2013. Changing Course: Ten Years of Tracking Online Education in the United States. Boston: Babson Survey Research Group.

Caputo, David A. 2014. "MOOCs and Political Science: Future Possibilities." Presented at the APSA Teaching and Learning Conference, Philadelphia. February 7-9.

Friedmann, Viktor, Pasztor, Anna and Kang, Hyungseok. 2014. "Comprehensive Participation in an Inter-institutional Environment: The Case of the Korea Foundation Global E-school in Eurasia." Presented at the APSA Teaching and Learning Conference, Philadelphia, PA., February 7-9.

Levinson, Nanette S. 2014. "Online Learning: Professional International Affairs Education Trends and Tips." Presented at the APSA Teaching and Learning Conference, Philadelphia, PA. February 7-9.

Moats. Sara. 2014. "The Political Science Online Classroom: Innovation and Design." Presented at the APSA Teaching and Learning Conference, Philadelphia, PA. February 7-9.

Quirk, James M. 2014. "Learning from MOOCs: Lessons for the Rest of Us." Presented at the APSA Teaching and learning Conference, Philadelphia, PA February 7-9.

Stangl, Chris A. 2014. "Distance Learning and Condensed Format Courses.” Presented at the APSA Teaching and Learning Conference, Philadelphia, PA. February 7-9.

Wagner, Kathy D. 2014. "Government and Politics Online: A Deliberate Path toward a Virtual Classroom." Presented at the APSA Teaching and Learning Conference, Philadelphia, PA. February 7-9.

Wukich, Clayton, Suzanne L. Frew and Alan Steinberg. 2014. "Teaching Key Elements of Decision Making Online for Homeland Security and Emergency Management." Presented at the APSA Teaching and Learning Conference, Philadelphia, PA. February 7-9.

Yount, Mary Beth, and Lorraine A. Cavaliere. 2014. "A Comparison of the Outcomes of Online and On-Ground Service Learning on Student Global Understanding and Citizenship." Presented at the APSA Teaching and Learning Conference, Philadelphia, PA. February 7-9.

\section{DIVERSITY, INCLUSIVENESS, AND EQUALITY}

\section{Boris E. Ricks, California State University Northridge Jessica L. Aubin, SUNY, University at Albany}

The eleventh meeting of the Diversity, Inclusiveness, and Equality (DIE) track at the 2014 APSA Teaching and Learning Conference focused on issues of diversity and inequality as they relate to pedagogical, classroom, departmental, and institution-wide matters from multiple perspectives. The DIE track hosted 16 participants and 10 research papers. Track paper titles included "The Importance of LGBT Inclusion in the Classroom;" "Teaching Race in Introductory American Government and Politics;" "From Gutter to Fisher: The Contradictions of Diversity as it Applies to Historically Black Colleges and Universities (HBCUs);" "Teaching Educational Inequality through a Civic Engagement Perspective: Integrating Diversity, FaithBased Principles, and Service;" "Empowering Students to Address Punishment and Inequality: A Case Study of the Inside-Out Prison Exchange Program;" and "African-Americans and Study Abroad Programs in Political Science," to name a few. Several track discussants provided constructive criticism and useful feedback to the presenters. Significant and meaningful dialogue focused on the meaning of diversity, teaching methods, student learning outcomes and diversity, inclusive supplemental resources, and campus climate issues.

\section{Diversity}

The DIE track broadly uses the term "diversity" to refer to several demographic variables, including, but not limited to, race/ethnicity, religion, color, gender/sex, national origin, disability, sexual orientation, age, education, geographic origin, characteristics, socioeconomic status, and cultural heritage. In the paper presentations and the discussions that followed, the DIE track found the broad use of diversity important for empirical and pragmatic aims. The pedagogical significance of introducing cross-cultural methods and cutting-edge approaches into the political science classroom addresses the increasing demands of demographic change in the global context. Track discussants concluded that learning outcomes motivated by diversity assist our endeavor to meet the challenging demands of a discipline influenced by extreme and noteworthy demographic shifts.

\section{Teaching methods}

Teaching students about race, ethnicity, gender, LGBT issues, and politics in the political science classroom can be a challenging exercise. Several track participants highlighted those challenges, and the summaries follow: (a) Race and ethnicity are key to understanding important and fundamental documents, institutions, bureaucracies, and government agencies. By focusing on empirical evidence political scientists are able to teach about race as a fundamental component of the founding of this country. So why not teach about race? (b) Women in political science do not achieve the same level of success as men. Their ranks among full professors are lower; their teaching evaluations by students are often more critical; and they hold less prestigious committee appointments as their male counterparts. How should faculty present themselves and their identities when teaching courses related to race, ethnicity, and or gender? How do we account for differences in college/ classroom demographics when trying to engage these topics? (c) It is increasingly important to encourage deep and critical thought about inclusiveness across diversity topics. The political science classroom should be a safe place where students can engage and explore different attitudes in a way that they can see individuals as part of an in-group rather than an out-group. Intersectionality topics, LGBT concerns, alternative lifestyle preferences, disability rights, and other identity issues warrant open, honest, and civil exchanges in the classroom.

\section{Student learning outcomes and diversity}

The DIE participants discussed the importance of incorporating diversity into student learning outcomes (SLOs). SLOs clearly state the expected knowledge, skills, attitudes, competencies, and habits of mind that students are expected to acquire at an institution of higher education. Transparent student learning outcomes statements are specific to institutional, college, department, and program level;

- clearly expressed and understandable by multiple audiences;

- prominently posted and widely distributed; updated regularly to reflect current outcomes; and receptive to feedback or comments on the quality and utility of the information provided.

The political science curriculum should prepare students to demonstrate an understanding and respect for economic, sociocultural, political, and environmental interaction of global life. Students should be able to demonstrate an understanding of relationships between diversity, inequality, and social, economic, and political power both in the United States and globally; demonstrate knowledge of contributions made by individuals from diverse and/or underrepresented groups to our local, national, and global communities; consider perspectives of diverse groups when making 
decisions; and function as members of society and as professionals with people who have ideas, beliefs, attitudes, and behaviors that are different from their own.

\section{Inclusive supplemental resources}

Inclusive supplemental resources within political science classrooms help facilitate the integration and transformation of knowledge about individuals and groups of people into specific standards, policies, practices, and attitudes used in appropriate cultural settings to increase the quality of public goods and services. The DIE track participants believe political science curricula and instruction should recognize and incorporate race, color, ethnicity, culture, traditions, sex, gender, age, sexual orientations, economic condition, and lifestyle. Inclusive supplemental resources must acknowledge and embrace differing perspectives as a core element of diversity. Inclusive supplemental resources enable faculty to use global, cross-cultural, and representative teaching and learning methods. Incorporating diversity as content encourages deeper levels and higher order teaching and learning. Diverse and representative textbooks and other resources are important teaching tools for expanding the learning experience.

\section{Campus climate}

Campus climate issues have surfaced at campuses around the country (e.g., University of California, Los Angeles, University of California, Irvine, University of California, San Diego, University of Michigan, and University of Texas). Campus climate is a measure of the campus environment as it relates to interpersonal, academic, and professional interactions. In a healthy climate, individuals and groups generally feel welcomed, respected, and valued by the university. A healthy climate is grounded in respect for others, nurtured by dialogue between those of differing perspectives, and is evidenced by a pattern of civil interactions among community members. Not all aspects of a healthy climate necessarily feel positive-indeed, uncomfortable or challenging situations can lead to increased awareness, understanding, and appreciation. Tension, while not always positive, can be healthy when handled appropriately. Conversely, in an unhealthy environment, individuals or groups often feel isolated, marginalized, and even unsafe. DIE track participants believe campus climate issues further complicate teaching and learning about diversity issues in the political science classroom.

\section{Recommendations}

The 2014 DIE track participants highly recommend that the Teaching and Learning Conference Program Committee host a preconference short course that focuses on issues of diversity, inclusiveness, and equality in the political science classroom. Critical scholarship, teaching, pedagogy, and classroom instruction on race, ethnicity, gender, LGBT issues, and otherness are significant components of cross-cultural awareness in the discipline and help meet the sensitive demands of the global context.

GRADUATE EDUCATION: TEACHING AND ADVISING GRADUATE STUDENTS

\footnotetext{
Allison H. Turner, West Chester University

Jennifer Kelkres Emery, University of West Florida

Ann Marie Mezzell, Alabama State University

Joshua A. Green, University of California, Berkeley
}

The 2014APSA Teaching and Learning Conference's call to action for participants to teach inclusively and integrate multiple approaches featured prominently in the Graduate Education track's discussion. Research highlighted potential challenges and opportunities for graduate education in political science and public affairs and identified a single common theme: graduate programs must rethink structure, curriculum, and incentives so that they better meet the employment and skills requirements of a fast-changing labor market. In particular, there was consensus that programs should recognize different groups of students within a single program who may have different professional ambitions and goals. Several papers sparked discussion relating to the relationship between economic conditions and graduate education. To prepare graduate students for a dynamic labor market and changing workforce, graduate education programs need to be versatile and responsive. Strategies for student engagement, curriculum development, and pedagogy need to reflect the changing professional standards, career aspirations, and learning styles of an increasingly diverse student population.

Mitchell Brown's research observes that the attainment of a tenure-track position for graduate students pursuing a degree in academia is a major indicator of the quality of graduate education; however, there is no consensus among graduate programs regarding how to best help students accomplish this. She addresses the importance of graduate student methods training and publication skills as tools for attainment of tenure-track jobs. Her research identified a combination of required programmatic methods training and publications as the best indicators of success. Discussants remarked on the apparent "ratio shift" between available tenuretrack positions and one-year (or postdoctoral) positions. Some noted that the shift presents particular challenges for graduate students entering the market, as well as for faculty concerned with their students' chances of placement.

The work of Josh Green, Linda Alvarez, and Jennifer Kelkres Emery speaks to the challenges of preparing future political science academics for the classroom. They identify a number of trends affecting graduate education, including greater diversity in student populations, increased financial pressure on that population, and a competitive job market that demands more of graduates. These trends require instructors who are able to transition students out of the traditional passive role of receiving a lecture. The authors recommend that new instructors should be encouraged to design active teaching modules that can be easily integrated into future courses. The authors presented three examples of such active teaching modules from their own classroom experience. These and other innovative pedagogical approaches prepare students to teach actively. Discussants agreed that faculty need to serve as models by demonstrating openness to developing instructional approaches.

David Ramsey and Jocelyn Evans furthered the conversation on the changing nature of the political science and public affairs graduate student population. Their research calls attention to the challenges faced by graduate education programs to be responsive to various student learning styles and preferences while maintaining the integrity of a traditional graduate experience. Track participants noted that job security and career advancement concerns often motivate midcareer professionals and working parents to pursue graduate work. Because of family and job commitments, these students may find it difficult, if not impossible, to take part in traditional campus-based courses. If departments hope to attract and serve these students, then 
successful adoption and integration of distance-learning technologies is paramount.

Similar to the challenges associated with a changing student population highlighted by other presenters, Ann Mezzell's research addresses the complexity of developing pedagogical approaches and delivery mechanisms that cater to a discipline with a growing number of subfields and professional vocations. She explores the role of terminal political science and related master's degree programs within higher education. Her work draws attention to the obstacles involved in matching curricular design with diverse postdegree career pursuits. Panelists noted that although students pursue the degree for various reasons, faculty members tend to treat the MA as a predominantly academic (rather than professional) degree. Mezzell's analysis reveals a need for input from assessment coordinators and directors of graduate study. Such input, she suggested, might better enable faculty members to prepare students for entry into the workforce as well as further academic study.

Allison Turner's research explores the challenges associated with incorporating information literacy into the curriculum of graduate programs. As the expectations of graduate students within our discipline expand, so does the definition of information literacy. Graduate students, in both masters and $\mathrm{PhD}$ granting institutions, regardless of postdegree career aspirations, need to communicate and interact productively with a diverse and changing workforce and citizenry. Panelists discussed the role of information literacy in civic engagement, noting that these competencies are universally required for students of political science and public affairs graduate programs. Ensuring that the curriculum of our graduate program keeps apace with such rapid change is both a challenge and an opportunity.

In addition to proposing new avenues for research, we also developed broad, institutional solutions to address these challenges. John Ishiyama had already taken the initiative to invite Philadelphia-area practitioners of graduate education, defined as deans of graduate studies, to our Sunday session at the 2014 conference. Although none were able to attend, we decided that it would be a great practice to repeat the experiment in future years and expand it by adding a workshop for them to discuss challenges they face. We would also like to invite them to attend part of or our entire panel to listen to the new research evaluating graduate education and its role in the profession.

We collectively want to reinforce the idea that there are a set of skills that are timeless, versatile, and appropriate for MA, MPP, MPA, MIA, MSA, and PhD graduate programs: oral and written communication, critical thinking, and analytical skills. Of course, the nature of those skills is changing as technology modifies the delivery mechanisms for information. As faculty, we have to develop curricula to accommodate new modes of communication. These modes require speaking in a captivating manner about yourself and your research; adjusting to new standards for the use of emergent presentation systems and techniques; social media; and facilitating discussion and participation in synchronous online courses (using video technology like Scopia or Blackboard Collaborate).

Underlying the broad range of concerns addressed was a common acknowledgment of the difficulties inherent in the graduate student mentoring process. Panelists generally agreed that faculty face numerous challenges-stemming from the lack of standardization of graduate program design and outcomes, confusion regarding designated responsibilities for graduate student professionalization, and competing career concerns-in advising students on how to best prepare themselves for competitive job market conditions. Nonetheless, the achievement of more cohesive student guidance messages, as well as "high impact" graduate education practices, is within reach. By seeking additional knowledge of the political science graduate experience, including its advertised purposes and outcomes, faculty can better assist students in the areas of professionalization and proactive self-marketing. Further inquiry, whether carried out by individual researchers, or by an APSA working group, might include specific tasks such as: (1) the collection of curricula vitae for the establishment of additional links between educational preparation and job placements, (2) the analysis of departmental website statements regarding program curricula and mission statements, (3) the development of surveys for the department heads, students, and employers about job training and placements, and (4) the provision for a future APSA Teaching and Learning Conference workshop, or focus group, for the discussion of these topics. Please note that the Journal of Political Science Education encourages submissions on the subject of graduate student training, professionalization, and career tracks.

\section{INTEGRATING TECHNOLOGY INTO THE CLASSROOM}

Cali Mortenson Ellis, University of Michigan, Ann Arbor

Ian G. Anson, Indiana University, Bloomington

Jeanine E. Yutani, University of Southern California

The use of technology in the classroom is almost taken for granted by most political science instructors. From PowerPoint slides to clickers to smartphones, however, the use of technology has evolved into a standard part of modern education. The dependence on technology for both students and teachers has and will continue to increase as more classrooms shift to online or hybrid (part inclassroom, part online) formats, and as class sizes continue to grow. With these developments comes a greater need for educators to not only be familiar with more technological solutions to classic classroom problems, but to also be more judicious in their application of new technologies.

All too often, the evaluation of classroom technologies is lacking. What actually works to motivate students and improve learning outcomes? To help answer this question, participants in the Integrating Technology in the Classroom track presented their own research on the use of various well-known and obscure technologies in political science classroom settings. Topics included using screen capture technology to provide student feedback, employing clickers to enhance student engagement, enhancing classroom interaction through Facebook campaigns, "flipping" the political science classroom, and much more. Presenters shared practical advice and discussed the potential issues faced when integrating technology in the classroom. As users of technology and scholarly evaluators of effectiveness, it was clear to track participants that this is a rich area of potential research.

\section{Using technology with intention}

A topic that arose repeatedly throughout many discussions was the importance of making measured consideration when implementing and integrating technology both inside and outside the classroom. Track participants concluded that with the numerous technological options available to educators, being selective about what tools to use is becoming ever more important. 
As noted earlier, both students and teachers will depend on technology as more classrooms shift to online or hybrid formats and as class sizes change. Therefore, educators need to be familiar with the technological solutions to classic classroom problems, and especially judicious in their application. This careful use of technological options was a focus of the paper, "Undergraduates \& e-Books: What Students Have to Say about Their Experiences with Digital Texts," by Jennifer Hopper of Washington College. In her multiyear surveys of undergraduate students at two institutions, Hopper found that many of today's students are comfortable with e-books, but that there is not universal acceptance of e-books as a replacement for regular textbooks. The technological infrastructure in which the e-book is embedded can be an important factor to their acceptance. Students appreciated the opportunity to highlight, make notes, and copy text from the e-book, a feature of the specific textbook used-but only when the technology worked. When it did not, faculty became "tech support" for students using unfamiliar software because campus IT departments had little knowledge or understanding of the tool.

The use of technologies that are already familiar to students was a focus of "Clickers and Twitters: Re-Shaping Assessment and Feedback Practices through Technology" by Alison Statham. Statham and her colleagues at DeMontfort University in Leicester, United Kingdom, are in the midst of evaluating the pedagogical uses of two of the most popular social media platforms-Facebook and Twitter. These tools were selected because they were more familiar to students than the university-developed Blackboard system. Rather than having to learn yet another technology, professors may consider adapting existing commercial technologies to their needs. Statham found that the opportunity to contribute to a Facebook group helped establish "a sense of community or ownership," but was not without drawbacks, including lack of participation and privacy concerns.

A workshop presented by Jeanine Yutani of the University of Southern California demonstrating how instructors can more effectively use PowerPoint as a teaching tool in political science and international relations courses echoed the value in adapting existing technologies to improve the classroom experience and student learning outcomes. Research has shown that students prefer courses and teachers who use presentation software, and Yutani's workshop showed simple techniques to help streamline the use of PowerPoint to make it more useful for both students and teachers. Retooling the way many instructors use a readily available instructional technology can facilitate student retention and enhance understanding of complex ideas and concepts often found in political science courses.

This point was also made by Kristen Abastis McHenry of University of Massachusetts Dartmouth in "Feminism and Facebook." McHenry describes how she used Facebook to engage her students in a real-world social media campaign about feminism, the topic of her course. The use of Facebook presented a number of pedagogical questions about group access, IRB approval requirements, and the limits of free speech on campus, particularly around potentially sensitive subjects. Each of these issues must be carefully evaluated by instructors considering using Facebook in a learning setting, despite its ubiquity and ease of use.

This underlines how educators must consider a number of factors when selecting technologies they may decide to use. First, the learning goals of a particular course may be more suited to the integration of some technologies over others. Technology should not be introduced simply because it is available, but should be used to enhance the learning environment.

Several of the papers presented exciting examples of how technology can be integrated into active learning goals. In "Election-Night Broadcast: Integrating Technology and Active Learning in a Larger Learning Community," Brian Roberts and John Williams of Principia College describe a collaborative effort to engage political science students in a student-led live radio broadcast of national election night coverage. When students took on the role of "expert" commentators, they turned their academic study of the Electoral College, American political parties, and research on specific state races into a real-world event in real time. Students were highly enthusiastic about the opportunity to apply technology to a real-world setting, reinforcing learning outcomes in a unique way.

In "Flipped Learning: A Springboard into the Deep End of Learning?" Rebecca Deen of The University of Texas, Arlington, describes her inclusion of technology into a "flipped" version of her course. Developed in the science, technology, engineering, and mathematics fields, flipped or "inverted" instruction requires students to engage with material outside of class and complete assignments in-class, when they can consult the professor directly at challenging points. From a technological standpoint, this means that instructors may record "mini-lectures" and post them to a course website. Deen found that students both felt that they learned more and worked harder than in a traditional lecture-and-homework format class, and that flipped methods worked best for specific learning goals such as class group projects, rather than as the default method of instruction.

A second consideration for educators surrounds access to technology. Although some tools are widely available, using others may be inordinately time intensive or cost prohibitive for instructors, students, or institutions. "Lights, Camera, Learn: Understanding the Role of Lecture Capture in Undergraduate Education," by Zachary Baumann and Daniel Mallinson of Pennsylvania State University, describes an evaluation of video lecture capture software provided by Penn State's Education Technology Service. In a large introductory lecture class, students were given the opportunity to view automatically captured video of course lectures. Whereas some instructors may assume that students use videos as a shortcut to avoid attending class sessions, Baumann and Mallinson found instead that there was little correlation between later viewings and class performance. Students who watched the videos repeatedly did not tend to improve, possibly because they did not understand the concepts in the first place. The videos may be especially helpful for nonnative English-speaking students, providing them with chance to review material without the pressure of simultaneous translation and learning. Ultimately, different students accessed the videos for different reasons, a finding that obscured broader empirical patterns. This is indicative of a broader point: when seeking to understand the impact of technologies on student outcomes, we must investigate fine-grained patterns and eschew the assumption that all students will experience technology the same way.

In line with this idea, a third consideration for instructors is that integrating technology requires not only considered application, but also considered reflection as to its effectiveness.

In "Hands-On with Prediction Markets in the Political Science Classroom," Cali Mortenson Ellis of the University of Michigan, Ann Arbor shared the results of an experimental evaluation in a classroom setting. In the evaluation, students were divided into 
treatment and control groups and assessed for their engagement with a web-based prediction market tool, as well as their actual knowledge as a result of their use. One surprising finding was that female students were less interested in prediction markets overall, trading less frequently than their male counterparts. But even those women who traded less frequently had similar outcomes to their male counterparts, indicating that their strategies were more effective. Evaluations such as these indicate that technology must be evaluated for effectiveness. Students, faculty, departments, institutions, and the political science field must share in a commitment to assess and improve on including technology in the classroom.

Technologies aimed at improving teaching or student experiences both inside and outside the classroom are sure to continue developing at a staggering rate. For many educators, it seems that just as they become comfortable with one program or platform, another one is introduced that claims to be better, faster, or more user-friendly. Evalutation of new technologies requires ongoing communication and information sharing between students and faculty, and within scholarly networks.

\section{Developing resource networks}

Sifting through so many technological options is daunting for many educators. Learning to use new tools can be time consuming, and, when added on to the many other responsibilities most faculty members face, may deter some educators from attempting its use. This situation demonstrates the importance of developing resource networks to support educators as they explore and integrate technologies in educational settings. As mentioned earlier, the judicious application of technology is required to prevent faculty from spending their time on tech support. Strong resource networks can ensure that technology aids instructors in streamlining their workflow, instead of miring them in constant troubleshooting.

At an institutional level, key players in these networks include campus administration, departmental leadership, library staff, institutional review board (IRB), and other faculty. Because many new instructors have little experience in the variety of tools available, track participants supported including training in using technological tools in graduate programs. Centers for teaching and learning can also help by exposing both new and experienced educators to the variety of options available and current pedagogical research.

Of utmost importance is the relationship between an institution's information technology (IT) support staff/department and its teaching faculty. Many IT departments are overwhelmed as the technological needs of colleges and universities continue to expand. IT departments are also acutely aware of the security concerns associated with new technology and may be wary of its implementation on an ad hoc basis. This reality demonstrates the need for greater institutional investment and support for exploration and experimentation in pedagogical technologies.

Track participants agreed that another part of these support networks should come from outside an educator's home institution. Meetings such as the APSA Teaching and Learning Conference are important opportunities for sharing information about educational tools available and their potential impact. In addition to conference meetings, publication is a key means for educators to share information about technologies and their application. One potential challenge to this, however, seems to lay in the limited outlets for pedagogical research in political science. Discussions emphasized the importance for scholars to undertake collaborative research and publishing about using and evaluating pedagogical technologies.

\section{Rethinking assessment}

Conversations about evaluating the application of various technologies in political science classrooms highlighted a few of important issues track participants felt should be addressed as part of on-going considerations when integrating technology in the classroom. First, a broader definition of "outcomes" is needed. Determining whether a technology improves student performance seems inadequate, as technology may have heterogeneous effects within and across varying populations of students. Measurement must be multidimensional and should draw from a variety of methodological approaches that consider students' perspectives alongside objective measures of improved learning outcomes.

A second issue reflected the fact that strategies of assessment may not keep up with the technologies. Traditional research methods may not be applicable to new pedagogical tools. Track participants cited challenges faced when conducting their research ranging from technological issues with simply trying to collect data based on new technologies, to the challenges of using quantitative measurements when qualitative measurements seem more telling, to encountering hurdles with an IRB not understanding how to deal with some technology-related projects or research. Networks for the successful implementation of technology may also be key for its successful assessment.

Including students in any assessments of integrating technology was a third area track participants discussed. Anecdotes about students preferring one professor who used technology in the classroom over another who did not seemed to echo from institution to institution. Technology should not only be reflecting of changing class styles and student needs, but also of student preferences as engaged participants in the learning process.

\section{Repersonalizing the classroom}

While many practitioners often worry about technology as a depersonalizing force in teaching, many track participants emphasized that technology should be considered as a method to "repersonalize" the classroom. In this digital era when most students seem more connected to their cell phones and laptops than they are to each other, participants wondered how technology could help enhance student/student and student/teacher interactions.

Track participants noted several key benefits of technology. First, technology can encourage and facilitate group work. Students are involved in many activities outside the classroom ranging from jobs to sports to internships, all of which can make meeting to work on a group project extremely difficult. Using an online collaboration program or class website can provide opportunities for students to work together even when schedules prohibit meeting as a group. The skills learned in such applications become important for students far beyond the classroom as professional communication often uses similar collaborative engagement.

Second, technology can address needs of different types of students. Some students may crave the anonymity of a large classroom setting, making clickers a useful tool to encourage engagement with the material. Lecture capture technologies provide the opportunity for students who have difficulty understanding at the pace of a traditional 
classroom to review a lecture they may have found particularly challenging. Technological tools can help students become active and engaged participants in the construction of knowledge rather than passive recipients of it.

Third, feedback is an area many track participants seemed to see significant potential for technology. Rachael Kim and Rachel Ellena, two undergraduate students of the late Craig Leonard Brians of Virginia Tech presented "Maximizing Their Pedagogical Potential: Clickers in the Large Classroom." As active users of a ubiquitous classroom technology, Kim and Ellena emphasized the strengths and weaknesses of clickers from their point of view. They emphasized the importance of connecting clicker questions to exam content and instructor responsiveness, and pointed out the attention benefits for students in a large lecture classroom.

Although many instructors continue to use the old "chicken scratch" method of making notes on student papers, slide capture technology enables educators to provide more nuanced and supportive feedback to students in a similar amount of time. In "Student Feedback using Screen Capture Technology in Political Science," Ian G. Anson of Indiana University shared the results of an assessment of a technology that makes grading papers both more effective and less time-consuming work. By using a simple, free screencapture technology when grading papers, instructors can avoid problems of miscommunication, confusing comments, and misread handwriting. Anson's evaluation showed that students were highly responsive to the technology and found that it improved engagement and feelings of instructor helpfulness and engagement. These types of technologies can be essential for students in online or distance education classrooms where the student may never directly interact with the instructor. Through these methods, track participants agreed that one-on-one teacher/student interaction can not only be facilitated, but also enhanced.

\section{Conclusion}

The 2014 APSA Teaching and Learning Conference provided a critical opportunity for scholars of teaching and learning to meet and discuss the future of pedagogy in the discipline. The implementation of technology in the classroom was a topic that extended far beyond the Integrating Technology track: virtually every discussion broached this subject in some form, be it concerns or optimism regarding MOOCs, the recognition of students' enthusiasm toward technology, or some other sentiment. Track participants were in strong agreement that the prevailing importance of technology in the classroom is only increasing. To that end, the track emphasized the need for greater resources for faculty to successfully implement technologies. Scholars across the discipline must continue to collaborate and learn from one another, sharing their experiences integrating technologies in the classroom. This process, occurring both formally through the publication process and faculty meetings, and informally through conversation, blogging, and other modes, will help to efficiently introduce technologies across political science.

As a discipline, we must be intentional about adopting and sharing technology because the potential benefits of our continued collaboration are enormous. The track's diverse presentations showed that through blogging, Facebook, clickers, video capture, and a number of other technologies, students and faculty alike have found their classroom experiences greatly enhanced. Bringing students into our conversations about technology also ensures that our use of future technologies will mesh well with their skills and preferences as "net-natives." Overall, the track looks forward to continuing our discussions with scholars and administrators within our departments, in multiple settings on our campuses, and across the field.

\section{INTERNATIONALIZING THE CURRICULUM}

\section{A. Olivia Miljanic, University of Houston Shamira Gelbman, Wabash College Deborah Ward, Rutgers University}

The Internationalizing the Curriculum track furthered the work completed in previous years on the conceptualization and implementation of internationalization in the discipline. The track had two primary goals: (1) raise awareness and disseminate knowledge about internationalizing the curriculum broadly in the discipline; and (2) share best practices. The track started by addressing the first goal, as initial discussions around the Roberts paper advanced a preliminary survey administered to participants in the 2013 APSA Teaching and Learning Conference. Subsequently, track participants outlined some of the primary challenges to internationalization in the discipline and explored responses to them. In addressing the second goal of sharing best practices, track discussions examined tools for internationalizing the curriculum and assessment of internationalization initiatives.

The preliminary survey on internationalizing the curriculum incorporated components of track discussions from previous APSA Teaching and Learning Conferences. One of these components was a definition for internationalizing the curriculum. Three definitional aspects prevalent in survey answers mapped onto ideas from past conference discussions: (1) using non-US perspectives, materials, authors, and cases; (2) exploring international connections in modern society; and (3) student exposure to other cultures and languages.

Survey results also prompted track discussion on challenges to internationalizing the curriculum. A survey question about integrating American politics into the comparative politics subfield elicited primarily negative responses. This illustrates vertical pressures against internationalizing the curriculum. Support for internationalizing often appears rhetorical. Another example is a situation where administrators encourage curriculum internationalization while simultaneously reducing language training opportunities. Vertical pressures are linked to US state legislatures' focus on directing resources to science, technology, engineering, and mathematics (STEM) training at the expense of internationalization.

A different set of challenges originates from the apparent duality in a commitment to internationalizing the curriculum coupled with a hegemonic view of the world favoring a US perspective and US-specific concerns. Previous years' track discussions emphasized the importance of internationalization to national interest and the use of internationalization as a means to expand state power. The Cook paper, based on the question of whether the way we teach international relations reinforces American hegemony, stressed the importance of separating internationalization from American foreign interest.

Track participants also discussed the challenge of reduced student interest in listening to the voices of other peoples, countries, and cultures.

In response to these challenges, track discussants formulated proposals for promoting internationalization. In presenting 
internationalization initiatives to college administrators, one possible area of emphasis is the necessity of training students to be savvy consumers and entrepreneurs. The field of nursing was used to exemplify the variety of professions that require cross-cultural competency.

Another perspective in promoting internationalization tools is study abroad as a lesson in how to travel. This is particularly valuable at a time when increasingly more professionals must travel for work. Furthermore, the current job market places students in competition with international job candidates. Accordingly, they are well served by a deeper understanding of the world.

In interactions with administrators, internationalization can also be framed as a way to attain the central goals of enhancing students' writing and critical thinking skills.

Track discussions around the Wright paper emphasized the study of microstates for stimulating student interest in international affairs and lobbying administrators. These states represent obscure yet fascinating cases that perform excellently in the areas of economic development, healthcare, and environmental sustainability. Wright's paper complemented Cook's by proposing the study of small states in international relations courses to counter-balance the US hegemonic view. In exploring the topic of sovereignty, small countries offer the alternative scenario of using sovereignty as a resource.

Other responses to the challenge of US centrism included the promotion of interdisciplinary research and teaching, a more ideologically balanced presentation of international relations, the curricular incorporation of nonwestern text and opportunities to listen to other people in their own language, and the complementarity of course modules from US and non-US perspectives.

In addition to identifying challenges to internationalization and appropriate responses, track discussions explored a variety of tools for internationalizing the curriculum. While study-abroad programs are the traditional means for achieving this, new pedagogical models and financial pressures are giving rise to alternative pathways for students to gain international experience. A notably innovative internationalization pedagogy that requires no travel is collaborative online international learning (COIL). This model, presented in the Johnson paper, cultivates students' cultural competency through courses that are taught collaboratively in the United States and at a partner institution abroad and involve extensive student interaction. COIL can be both a tool for internationalizing the curriculum and an effective strategy for addressing challenges to internationalization.

The Gann paper generated discussion around pursuing internationalization not merely at the course or program level, but as a concerted, college-wide effort. The particular college-level promotion tool analyzed included an internationalization checklist for course leaders and a cross-departmental peer-review process. Such an ambitious internationalization initiative poses both opportunities and challenges. On the one hand, it paves the way for institutionwide discussions of internationalization and resource-sharing across departments. Moreover, interdepartmental peer reviews promote interdisciplinary learning. On the other hand, the initiative presumes some preexisting level of administrative support and may undermine the inherent interdisciplinary of internationalization with checklist-style quality control measures that are conducted at the course level.

The internationalization checklist may also serve as an assessment tool, another major area of focus for the track. There was general consensus regarding the importance of assessment both to ensure the educative quality of internationalization programs and to gain support for them from administrators and other stakeholders who may not value internationalizing the curriculum as an end in and of itself.

Presenters called for ongoing, nuanced measures of learning outcomes rather than vague student endorsements immediately after short-term study-abroad and on-campus international experiences. Track members also discussed the importance of assessment at the program level, an intermediary step between the prevalent course level assessment and institutional assessment. A novel and potentially powerful suggestion was to evaluate the wider impact of internationalization programs on faculty and students beyond those immediately involved in them.

The Miljanic paper on the University of Houston's Certificate in Global Studies and Research program, which provides global exposure in part through interaction with speakers from multinational corporations and a capstone research project, raised interesting possibilities pertaining to the assessment of internationalization efforts. Although initially designed to encourage more study-abroad participation, the program no longer makes it a requirement; as such, it opens the possibility of a quasi-experimental assessment of learning outcomes and other benefits of the certificate for students who do and do not study abroad.

The Internationalizing the Curriculum track fulfilled its dual goal. Each participant took away a few ideas that would affect teaching practices, and the track engendered discussion of action items to disseminate internationalization more broadly throughout the discipline: (1) creation of a working group; (2) development of a short course at the APSA Annual Meeting; (3) creation of a task force with the goal of providing resources for information collection and dissemination and discussing definitions of internationalization that faculty members can use when approaching administrators; (4) development of a plenary discussion at the APSA Annual Meeting to raise awareness more broadly in the discipline; (5) transformation of the preliminary APSA website for internationalizing the curriculum into a more comprehensive website for the many faculty interested in internationalizing the curriculum who cannot attend the APSA Teaching and Learning Conference; (6) revisions to the survey on internationalizing the curriculum based on input from track participants and survey administration to the entire APSA community; (7) creation and dissemination of concise "how-to" booklets; and (8) increased collaboration between the APSA and the International Studies Association.

Participants reiterated the continued need for this track at the conference. Internationalization is always changing, undergoing ebbs and flows dictated in part by external market forces. It is the responsibility of track participants to acknowledge these fluctuations and educate other faculty on the value of internationalization. This process is a crucial step in disseminating internationalization throughout the discipline. Moreover, it increases the chances of success when promoting curricular internationalization to college administrators.

SIMULATIONS AND ROLE PLAY I: INTERNATIONAL AND DOMESTIC POLITICS AND THEIR INTERSECTION

David Yamanishi, Cornell College

Monti Narayan Datta, University of Richmond

Casey Delehanty, Florida State University 
Simulations represent a nexus between theory and practice, one that allows political science professors and political practitioners to capitalize on ideas, channel creative energy, promote conceptual understanding, and advance opportunities for problem solving across a range of topics. The value of simulation as a pedagogical technique, in our view, is not merely that students find it an engaging use of classroom time, but that putting students in an imagined context can help them escape preconceptions about politics and political science to internalize political dynamics and the challenges faced by policy makers. Not only did our track review a wide-ranging set of simulations that addressed political activities, such as campaigning and crisis management, and political concepts, such as bargaining and fairness, but we also set aside time, to "test-drive" one of the international relations simulations that we had assessed. By conducting Becki Elkins's "Donut Wars" as a group, we created a new frame of reference for evaluating the efficacy of simulations, allowing us to further reconsider some of the questions that had animated our earlier discussions (and, as one participant pointed out, allowed the forces of justice to prevail).

Several of our discussions turned on the question of whether realism and pedagogy are in tension with one another. Some participants' simulations contained complex, interlocking mechanisms intended to capture the multiple and conflicting influences that affect real policy makers (even if the storyline was sometimes imagined), while other participants preferred to isolate specific political dynamics in simplified scenarios to highlight their individual effects. Some level of abstraction from reality is unavoidable, but both approaches have value, perhaps at different points in a student's career in political science. A related dichotomy prevalent in our discussions that, in the end, we rejected is that between realism and playability; a well-crafted simulation with clear roles and rules should be able to be both empirically relevant and enjoyable (if perhaps challenging) to play.

Another frequent topic for discussion was how to prepare students for their roles in a simulation. Some participants have created rich sets of preparatory materials for their students to provide them with scripts that will, alternately, help them hew more closely to empirical analogues or suggest the range of strategic options available. Other participants prefer to use preparation for role playing as an opportunity to require students to gather and organize information about the actors whom they are imitating or referencing in their simulations. The former may require more advance preparation by the faculty member, but may also result in a more realistic simulation. The latter demands more discovery by students, which may itself be valuable, and may help to avoid the peril of over-constraining the students' behavior in the simulation by the professor's understanding of what would "really" happen.

We also discussed the pros and cons of several specific elements of simulation design: whether students with demonstrated talent should be assigned to critical roles, whether students should be assigned to roles contrary to "type," whether and how the professor should intervene in a simulation that may be going awry, whether students should dress the part in a simulation, whether and how students should work in groups or singly, and whether the professor should play an active or neutral role.

Finally, we considered ways to assess the success of simulations, particularly in an effort to move beyond measures of engagement and interest to accomplishment of more pedagogically central class goals. Debriefing is critical here: we should prompt students to express and assess the construction of the simulation's rules and roles, the crafting and evaluation of win and loss conditions, and the efficacy and prospects for differing degrees of success and failure of particular strategies. Lessons learned in simulations should be integrated with other teaching techniques and assessed via other course assignments. From the point of view of pedagogical scholarship, pre- and post testing of significant lessons that are addressed partly by simulation and partly by other techniques, in combination with varying the timing of a simulation exercise during the term from class to class, may be a valuable technique.

\section{SIMULATIONS AND ROLE PLAY II: ASSESSMENT AND METHODOLOGY}

\section{Patricia Stapleton, Worcester Polytechnic Institute Amanda Rosen, Webster University}

The Simulations and Role Play theme was split into two tracks, with the second focusing on "Assessment and Methodology." The bulk of the papers and discussion addressed the assessment of student learning outcomes, the methodology of assessment, and instructor motivations in selecting role playing and simulation activities for their classes. Overall, this year's track continued to develop ideas from previous conferences, namely: (1) best practices for assessing simulations, (2) the crucial role of structure and timing of games and assessment, and (3) student and instructor motivations during simulations.

\section{Use and structure of assessments}

A primary theme among the track's papers was how to assess a broad range of student learning outcomes. Pedersen's paper outlined several aspects to consider. By using role playing and simulations exercises, he explored how instructors can evaluate several factors, such as: social learning, acquisition of research skills, problemsolving skills, learning transfer, experiential learning, critical learning skills, and/or the ability to establish communities of learning among their students. Allendoerfer addressed the assessment of students' long-term retention of the course material, while Beers, Zappile, and Raymond, in their collaborative effort, concentrated on assessing student attitudes toward global empathy.

Although the theoretical rationale for simulations as a classroom tool is sound and studies suggest the success of active approaches to learning, we have been limited in our ability to make quantitative assessments of learning in specific simulations due, in part, to the small-N problem (Raymond; Biziouras; Allendoerfer). Without larger samples, our work is limited in its ability to claim generalizations about the role of simulations and games in learning. Other methodological issues were prominent in the discussion. Biziouras, for example, noted the importance of establishing a baseline of student understanding, to track learning and create more data. Much of the track discussion was solution-focused, with a strong emphasis placed on collaboration among instructors through swapping simulations and sharing data to help draw conclusions about effectiveness and value. A general consensus emerged over the course of the conference: instructors can use simulations to provoke a variety of learning outcomes but ambiguity remains about how to measure success properly in achieving those outcomes.

\section{Structure and timing}

Participants also considered the role that the structure and timing of a simulation or game might play in their effectiveness. Kulchitsky's paper illustrated how social networking technologies 
help create a written record of "thinking" both for the student and instructor during the simulation. Similarly, Vaccaro demonstrated how different technologies can create digital interactive texts, making a simulation customized for the course. As a result, the structure of these simulations generated different types of materials that can be used in evaluating specific learning outcomes and student participation.

Several presenters (Raymond, Allendoerfer, Biziouras, Stapleton) grappled with the question of timing within their papers, considering questions such as where in the course calendar should the simulation run and when outcomes should be assessed. Instructors may need to account for how the timing of the simulation-before, during, or after exposure to other course materials-can affect learning gains. And, although repeated assessments may help alleviate the small-N problem, participants questioned the effectiveness of using the same assessment questions over and over again. Measured improvements in student learning may simply be a consequence of repeated exposure.

Accordingly, track participants acknowledged a need to recognize that just as a diversity of qualitative and quantitative methods are valid across political science, so too should such methods be accepted in the assessment of simulations. As such, there is no "silver bullet" answer; instructors must evaluate the needs and constraints of each class in relation to the selected simulation.

\section{Student and instructor motivations}

Student interest and motivation in simulations became a recurring topic among the track sessions. Despite the focus on assessing learning outcomes, participants also acknowledged the value in making the learning environment "fun" by using these active learning techniques. The simulation on the advantages and disadvantages of quantitative analysis developed by Asal et al. highlights how reducing student resistance to difficult topics can be an objective in its own right. Nevertheless, although student engagement and experience (as well as their enjoyment) do matter, role playing and simulation techniques should not be considered in this manner at the exclusion of the potential impacts on learning. Participants acknowledged that instructors must take students into account when selecting teaching methods, in terms of: students' motivations and relationships in the classroom (Rosen and Kollars); student familiarity with different technologies (Kulchitsky); and student skill levels (Pedersen).

But instructors also need to be aware of their own interests and motivations in choosing pedagogic methods. In the last panel, Stapleton presented her experience with "flipping" her classroom as a way to respond to concerns about the impact of large class size on student evaluations of teaching. The ensuing discussion touched upon the different pressures that instructors face in selecting teaching methods, including: tension between implementing institution-wide assessment techniques and their effectiveness and consequences; the need to broaden the definition of assessment; and the potential of employing simulations to help overcome gender issues. In short, the use of role playing and simulation techniques and the efforts to assess them boil down to balancing the need to demonstrate results methodologically while maintaining the big pedagogical picture.

\section{Recommendations}

In light of the ongoing conversation on the value and effectiveness of role playing and simulations in the political science classroom, thefollowing recommendations are offered. First, instructors should seek out opportunities for collaboration. Collaboration is useful not only to increase our $\mathrm{N}$, but also to develop resources and outcome assessments, improve games (Beers, Zappile, and Raymond), and create occasions for interdisciplinary work (Vaccaro; Pedersen). To that end, small simulations that run over one class (rather than week- or semester-long simulations) would be easier to develop and use collaboratively to develop larger Ns. The Active Learning in Political Science blog can be used to help develop such collaborations and share data (http://activelearningps.wordpress.com/). Note, however, that an absence of assessment data does not make or break the effectiveness of a simulation, or a potential publication for that matter. Quantitative analysis should not be an ideal if the analysis does not prove to be meaningful.

Second, the continued emphasis from this track that there must be clear intentions during game development progressed to include the importance of instructors having clear objectives for the structure and timing of games and of their assessments. By addressing these variables, teachers recognize that the timing of the game can influence learning outcomes, and in turn, they can develop better assessment techniques.

Finally, despite the emphasis on learning objectives and assessments, the participants agreed that student and instructor motivations are important factors in game development and assessment. As instructors, we must challenge the notion that classrooms exist in a vacuum and recognize that students have to continue to interact with each other after the game ends, both in and outside of the classroom (Rosen and Kollars). We must also consider how the implementation of active learning techniques can have an impact on our own experiences as instructors. Collectively, these recommendations emphasize that both the use of simulations and their assessment require serious additional study to determine further best practices.

\section{TEACHING AND LEARNING AT COMMUNITY COLLEGES}

\section{Terri Desai, Glendale Community College Cirian Villavicencio, San Joaquin Delta College}

The Teaching and Learning at Community Colleges track explored a wide variety of issues. An overarching theme that emerged was that community college educators can be seen as first-responders to a variety of external pressures that will ultimately effect political science education at all levels. These pressures include curriculum and accreditation demands placed on educators by state agencies and four-year schools; the necessity of properly defining, measuring, and achieving student success; the divergent interests and abilities of the student body; and, relatedly, low levels of civic literacy and engagement. Participants agreed that, although these external pressures on our cohort present many challenges, they also present opportunities for innovation that can influence the discipline.

The track discussed the increasing influence of internal and external pressures from accreditation agencies, state offices, and professional associations that demand more accountability in the delivery and efficacy of our curriculum and programs. Although changes have been gradual, there is little doubt that faculty must play a central role in preparing their respective institution's responses. These changes are increasingly transforming faculties' roles and responsibilities and effecting our ability to teach and evaluate our students. How will we adapt to these changes in a way that will enable the discipline of political science to remain relevant in the future? 
We discovered that these pressures either created limitations or opportunities. Robert Harbaugh and Michael Robinson from the College of Western Idaho presented a case study that illustrated an opportunity. Faced with both internal and external pressuresa new institution with growing student enrollment, one full-time faculty member manning the political science department, and the need to create a comprehensive degree program that articulates to its neighboring four-year institutions-Harbaugh and Robinson created a program that focused on interdisciplinary collaboration. Given that a number of community colleges across the country have small political science departments (one to two full-time faculty), Harbaugh and Robinson assert that partnering with other departments can have both economic and academic benefits that not only streamline costs but also provide a pathway for students to complete degree programs. Their paper revealed that curriculum planning efforts have greater potential for success when faculty approach their tasks as an opportunity to learn from one another, to gather information and data, and to consult with colleagues with different expertise and experience. Recognizing that each institution has its own external and internal pressures, discussants agreed that the model that Harbaugh and Robinson propose would be more challenging to implement in established community colleges where its mission, relations with other departmental units, available resources, articulation agreements, and accreditors may become barriers to these types of collaborations. However, when favorable conditions exist, such collaborations should be seriously considered given their acknowledged benefits.

Marketization forces that demand higher quality and accountability with fewer resources are sources of additional pressure. For example, state mandates proposing dual-degree programs that allow high school students to simultaneously complete a diploma and earn an associate's degree are blurring the lines between secondary and postsecondary education. Community college faculty, where dual-degree programs exist, now see a significant portion of their student population come from the high school ranks. This added dimension makes it more challenging for community college faculty as they are (1) inadequately trained to teach high school students and (2) are required to teach these students who may not possess the skills nor the maturity to succeed in a college-level classroom. A.J. Quackenbush from Valencia Community College and Britta Nelson-Bleigh from West Virginia University attempted to find ways to assess their students' needs to adjust their teaching styles to improve the quality of teaching in the classroom. Unfortunately, this type of research becomes more difficult as community college student populations not only become much more diverse but also younger. Rather than focusing on teaching political science that demands higher academic rigor, critical thinking, and research skills, community college faculty, faced with the reality of teaching underprepared students, focus on teaching civics instead. In addition, the rise of professional development courses tailored to employers' specific needs is devaluing the liberal arts and social sciences. There is a trend where American government courses, traditionally seen as a mandatory general education class, are now offered as an elective, giving students the ability to bypass taking them. Clearly, the repercussions of not taking American government are grave. It will result in a society where citizens are uninformed and civically unengaged.

Another recurring theme of the track is the pressure that unprepared, underprepared, or disinterested students place on the curriculum and the educational environment. The sheer diversity of the working environments of the track participants was revelatory in this regard. In addition to the aforementioned faculty with high numbers of high school students, there were teachers from predominantly technical or trade colleges where political science is a required course with little or no meaning to the students; educators from colleges where the vast majority of the students cannot meet basic literacy requirements; and, representatives from colleges conforming more closely to a traditional junior college model.

Many students in introductory level political science classes at the community college level are not there by choice. Instead, they often find themselves required to enroll in a government class to further their degree requirements in another area such as education, social work, or communications. Some take the course because political science satisfies a basic social science elective for a technical degree. Most students have no intention of majoring in political science. Most likely, each classroom contains a combination of all these student motivations.

During the special track discussion "Roundtable: Education and Vocational Training" the focus was on making our courses relevant to those students who are required to be there but do not see the importance of the topic to their daily lives. Instructors spoke about giving students in vocational programs assignments concerning policies that would affect those professions. Others mentioned focusing on issues of wide appeal to the specific populations (e.g., hunting rights, marijuana legalization, or the death penalty) to stimulate interest in the government. Other participants talked about the need to continue to focus on the critical thinking skills that learning about government provides and that will be of ultimate value to the students regardless of their chosen professions.

A large percentage of the community college population lacks basic literacy skills necessary for productive engagement in class and the larger political world. Reaching unprepared or underprepared students presents a challenge and an opportunity for innovation as well. Jacquelyn Johnson (Olive-Harvey College, City Colleges of Chicago) teaches in a severely depressed economic area in which the vast majority of the student population is both woefully unprepared for college work and extremely disillusioned with government. Her paper presented a model for active learning aimed at involving her students in voter registration efforts. Her goal for the students was to increase their knowledge of the political system and to encourage them to participate. She had them research and share facts about the election and the candidates and then use those facts to persuade students campus-wide to register to vote. Her focus was on empowering her students to have political opinions. She persuasively demonstrated that students, regardless of their academic and socioeconomic deficits can, and will, think critically on matters that are important to them.

Similarly, Corena White (Tarrant County College, Trinity River campus) honed in on another type of unpreparedness: lack of civic literacy. She addressed the issues that arise in a climate where half of all states do not require a civics class to graduate from high school. She discussed the paradox in which we are in the midst of a digital, information revolution, but great swaths of our students remain politically illiterate and demonstrate very low levels of political efficacy. White finds the mainstream media complicit in this illiteracy due to their focus on infotainment and because the concentration of media ownership results in a situation where the media no longer serve its primary watchdog function. White also sees opportunity. She posits that the increased use of social media (such as blogs) can serve as the tool that empowers students to civic literacy. 


\section{Charge to APSA and recommendations}

Community college teachers, like their counterparts at four-year institutions, are faced with many challenges. Our experiences on the front lines uniquely position us to sound the alarm about threats to the discipline arising from curriculum, articulation, and socioeconomic pressures. Our charge to ASPA is to educate and empower its members regarding these important trends both regarding the threats and the opportunities that they present. As faculty, we have the ability and responsibility to steer the direction of the policy debate by informing our state legislatures and Congress of the negative impact of these policies. At the end of the day, the reputation of our profession is at stake and we cannot afford not to take action.

\section{TEACHING POLITICAL THEORY AND THEORIES}

\section{Kevin M. Cherry, University of Richmond \\ Daniel Mulcare, Salem State University \\ Asif Siddiqui, Peking University HSBC Business School}

In discussing the pedagogy of political theory, the 2014 participants acknowledged previous - and as yet unresolved-difficulties. These debates covered the tension between pursuing breadth and depth, the assignment of primary versus secondary sources, and the use of excerpts rather than full texts. However, the papers at this year's track, ably moderated by Michelle Deardorff, largely bypassed these controversies.

Perhaps the strongest consensus that arose was that there is no one right way to teach political theory. Some of this variety arises from particular circumstances-the institution, the personality of the teacher, the kind of students, the level of the course-but these diverse approaches also result from choices made by the instructors. One of the most frequently noted choices that professors have to make is between course goals that emphasize conceptual knowledge and familiarity with important texts and those that promote developing crucial skills, such as critical reading and deep thinking. These are not contradictory goals, of course, but to balance these can be difficult. There can also be, as some participants observed, a danger in trying to make political theory coursework acceptable-whether to students or administrators-by focusing on the acquisition of skills to the exclusion of content. Regardless of the particular objectives of a course, participants also agreed on the importance of designing syllabi and structuring assignments with these goals in mind.

One of the fundamental challenges presenters identified was helping students engage with political theory texts. Participants agreed that students' in-depth contact with the readings was crucial: part of our task as professors is to help students acquire an enthusiasm for learning. In addition to using sources from popular culture and contemporary and historical case studies, several innovative methods to increase student engagement were proposed. Some of these pedagogies used new technologies and going outside of the classroom, and others involved nothing more than old-fashioned pen and paper. Some presenters, such as Meg Mott and Tom Rozinky, suggested encouraging classroom debate and even conflict as a way of sharpening students' comprehension of the ideas being studied. Mott and Kristina Haddad argued for incorporating theatrical elements into the study of political theory, which would help students appreciate the plurality of perspectives that political action involves. In a more traditional manner, Benjamin Mitchell advocated the revival of the humanists' "Commonplace book" model. Through copying and commenting on the most important passages, this method invites students to appropriate the texts and make them their own. Another tension we recognized, then, was between the development of the internal, private life of the mind, and students' ability to communicate their discoveries to others.

Another key point of debate revolved around the place of political theory with the discipline itself. While participants offered differing opinions on whether theory better fit within the humanities or social sciences (perhaps being the keystone that bridges the two), there was general consensus that theory provides significant contributions to the discipline specifically and the liberal arts in general. As Tim Meinke's paper on teaching genocide, evil, and politics underscored, many of political science's fundamental questions can best be approached through the critical examination, evaluation, and definition of concepts. Although political theory does not hold the monopoly on the exploration of key ideas that are central to the discipline-such as democracy, justice, and virtue-it does have a comparative advantage in this realm.

Political theory's emphasis on reflection, mindfulness, and careful deliberation also serves as a central contribution to the discipline's efforts to assess student learning. Two different papers, one by Dan Mulcare and the other by Alison Staudinger, explored how Bloom's taxonomy could be used to examine the extent to which students were engaged in critical thinking. Like in-class debates, theatrical presentations of theoretical concepts, and the "Commonplace book" model, the use of Bloom's taxonomy invites students to respond to the text's main themes. These methods also enable instructors to observe students' critical understanding of often challenging readings and allow faculty to recognize students' mastery of course concepts as well as students' ability to develop their learning during the semester. These pedagogical approaches help faculty to recognize with greater frequency those areas where students struggle with the field's challenging ideas as well as identify the gaps in students' learning skills. In his paper, Asif Siddiqui noted that instructors should be aware of the threshold concepts and troublesome knowledge that students encounter in theory classes. The pedagogical methods discussed in the working group showcased how contemporary theory instruction recognizes students' limitations and enables them to overcome these obstacles.

Insofar as political theory courses have different goals, they will use unique modes of assessment. Along with the standard methods associated with the measurement of student work, such as surveys, graded submissions, rubrics, and pre- and posttests, the methods unique to political theory-modeling ideas, critically reflecting on individual practices, and philosophically examining different pedagogical approaches - can also provide the discipline with valuable information about which teaching methods will best serve our diverse student bodies.

When many colleges and universities are reducing budgets, it can be hard to make the case for supporting political theory courses. As the track members discussed, political theory is an integral part of the political science curriculum and can certainly help make citizens more reflective, but it also makes a broader contribution to a liberal arts education by helping students develop the ability to read carefully. A growing number of universities are primarily focusing on improving the writing skills of their students, and therefore a greater amount of limited resources are being put at the disposal of writing centers. What is often overlooked is that other skills, such as reading and speaking, are also central to the students' academic success. 
In fact, reading, speaking, and writing are closely connected. Reading helps teach sentence structure, proper use of words, vocabulary, and numerous other important items. Speaking about and defending ideas also help the development of critical thinking and organizational skills as well as filtering out ideas that cannot stand up to scrutiny. Close reading, the main staple of political theory, can play a major role in developing all of these competencies. This contribution of political theory needs to be communicated to institutional leaders as well as to students: as political theorists, we must show why close reading is worth the extra time required to do it.

Looking to future considerations for teaching political theory, we felt that effective student assessment techniques are beneficial to educators in political theory; therefore, it is important to develop rigorous yet useful ways to evaluate students' work. Although welldesigned examinations, among other assessments, can test grasp of concepts, it is necessary to find ways to better measure our promotion of deep learning. For instance, the teaching methods discussed during our track highlight that theory professors continue to use pedagogies that allow for an immediate awareness of students' understanding of the material, and these low-stakes opportunities to direct student learning proved to be a unifying theme of our discussions. Indeed, political theory-with its emphasis on self-reflection, critical reasoning, and careful mapping of an author's argument-is well suited to assist in gauging meta-cognitive development among students. As an example, as instructors focus more on the implementation and evaluation of explicitly stated goals and objectives for each course, theory's methods of inquiry can assist in the process of connecting our assignments to our anticipated outcomes. Theory, then, is not only central to the development of critical reading, writing, and verbal skills, but it also provides essential tools to the assessment of them.

Political theory also highlights that assessment can only go so far. After all, one of the essential components of political philosophy is to examine those areas that cannot be easily quantified or measured, and theory has a role to play in challenging the potential over-emphasis on observable outcomes. Although well-constructed alumni surveys could reveal some essential information in this regard, the lasting effects of teaching may not be easily traced. (An alternative means of assessment we discussed was peer evaluation of teaching, which can help us communicate content to students more effectively.) As we continue to consider our contributions to the discipline and the academy, in future theory tracks, it may prove beneficial to examine our role in the assessment movement. While our conversations touched on the ways that theorists offer unique insights to the methods that could be used to evaluate students' progress, theory also plays a role in the critical interrogation of the assessment movement's purpose and efficacy. An interesting and necessary jumping off point in future discussions may revolve around whether assessment provides us with important tools or serves as a way to further negatively limit our field.

\section{TEACHING RESEARCH METHODS}

\section{Mary P. McGuire, State University of New York, Cortland}

A series of themes emerged from the presentations and discussions in the track on Teaching Research Methods (TRM). TRM members focused on a set of guiding questions from which the themes emerged: What should the content of an introductory course in research methods contain? How can technology be used to strengthen student learning in research methods? How can the fear of, and difficulties in the ability to grasp, math, which plagues students, be balanced with what needs to be taught in political science research methods? When in their undergraduate careers should students take a research methods course? How can librarians' role be enhanced in the interplay between methodology and research techniques?

The discussions on content were broad and ranged from the general to the particular. They were, of course, informed by the papers presented. General themes included the basic concept of corroborating causal inferences (Dopp 2014) and the balance between quantitative and qualitative methods (McGuire 2014). While the particular topics focused on specific approaches, such as scaling analysis (Kilburn 2014) and the use of Excel's statistical capabilities (Guo 2014).

Discussions regarding common student fears of math balanced the need to teach students that learning is hard and requires significant effort on their parts, against the need to encourage them to overcome frustration and learn a valuable tool. Track members were interested in helping students realize the value of understanding statistics and other methodological approaches for their careers, as well as, for their personal roles as consumers of information. Whereas the papers did not specifically address this theme, it was a recurrent theme across discussions. The Lau-Bertrand (2014) paper informed this discussion by considering the impact of instructor continuity on student learning and satisfaction across research methods courses.

Panel members considered when in students' undergraduate careers introduction to research methods was most appropriate. On the one hand, there was concern raised that an introduction late in the curriculum would mean that there was little chance for the skills acquired to be reinforced and that the importance of methodology to political science would be underappreciated. On the other hand, early courses that take advantage of students' interest in politics itself can have the advantage of helping students to see why it is worth their effort to take on the task of learning methodology.

The group devised three recommendations for research methods in political science based on their discussions at the meeting. First, research methods should include more than statistics. Methods should be more broadly understood to include the basics of finding reliable data and literature within the vast sea of easily accessed, but often suspect, data and information available to students through the Internet. Students should learn to discern what material does and what material does not meet the standards for inclusion in academic political science research. In this area the interplay between librarians and political science faculty can be extremely important. The idea that research methods should be more than statistics also meant that students need to be introduced to a vast array of methodology that has informed political science research. In addition to statistics, students need exposure to a variety of qualitative methodologies, such as participant observation and content analysis that have been important throughout the history of the discipline. They should also be exposed to approaches such as scaling, which relies on numbers to create powerful visual displays.

Second, the teaching and learning of research methods should not be limited to a course, or a set of courses, but should be taught across the political science curriculum. Ideally, instructors within each area of political science would teach and reinforce methodological approaches within their classes. Three papers highlight approaches to this. Guo experimented with teaching students to use international statistical data in his Introduction to International Relations course while Auerbach (2014) developed internship opportunities in which students' primary internship responsibilities revolved 
around conducting and analyzing research in the field. Both of these courses required students to use statistical methodology-in classes that were not primarily methodology courses. Arbour and Ackerman, in researching the ways in which students were taught to find, use, and evaluate secondary research sources, found several ways in which course instructors incorporate research methods from annotated bibliographies to reviews of academic journal articles. Each of these examples demonstrates different ways in which the recommendation that research methods be infused in the political science curriculum can be met. However, beyond the mechanics of assuring that methodology was an ongoing part of undergraduate political science education, members of the track asserted that political science departments should articulate where research methods were being taught within their curriculum and exactly what methods students were learning before earning their undergraduate degrees.

The third recommendation was that political science departments should consider the advantages and disadvantages of a variety of delivery modalities for methodology courses and content. As students learn differently, it is important that the way in which difficult material is offered not be limited to a single modality. Both the Ault (2014) and the Daigle and Stuvland (2014) papers examined a variety of teaching platforms. Ault concentrated on online approaches to delivering material. The concept of filming "chunks," short lessons in which the instructor demonstrated a concept, that students could watch and re-watch as needed, stood out as a technique particularly well suited to teaching difficult material in a way that would hold students' attention. Due to their brevity, students would have an opportunity to control how much repetition they required to grasp a concept. Daigle and Stuvland compared the outcomes of students in large, small, and online classes. Using the vast variety of delivery modalities offered to instructors through technology is an opportunity to increase the number of students who succeed in learning methodology.
The 2014 Teaching and Learning Conference afforded members of the TRM track the opportunity to share their research, observations, and successes, as well as their concerns and difficulties. It resulted in three days of productive and supportive discussions and ultimately led to the recommendations listed here. The space to focus on questions of teaching in political science with colleagues provided track members with the ability to contribute to the development of best practices in teaching methodology.

\section{R E F E R E N C E S}

Ackerman, Erin and Arbour, Brian K. 2014. "From Library to Learning: Teaching Students to Use Scholarly Research." Presented at the APSA Teaching and Learning Conference, Philadelphia, PA, February 7-9.

Auerbach, Arthur. 2014. "Constructing a Research Internship Program as a Means of Promoting Experiential Learning." Presented at the APSA Teaching and Learning Conference, Philadelphia, PA, February 7-9.

Ault, Michael. 2014. "Teaching Research Methods using Synchronous and Asynchronous Online and Hybrid Approaches." Presented at the APSA Teaching and Learning Conference, Philadelphia, PA, February 7-9.

Bertrand, Julia Lau. 2014. "Follow-Through in the Research Methods Curriculum: Reinforcing Research Skills through Teaching Continuity." Presented at the APSA Teaching and Learning Conference, Philadelphia, PA, February 7-9.

Daigle, Delton T., and Aaron Stuvland. 2014. “Teaching Research Methods across Delivery Modalities - An Introduction to a Research Design that Compares Large Classes, Small Classes, and Hybrid Distance Offerings." Presented at the APSA Teaching and Learning Conference, Philadelphia, PA, February 7-9.

Dopp, Kathy Anne . 2014. "How to Empirically Corroborate a Causal Inference: What is Missing in Political Science Education?" Presented at the APSA Teaching and Learning Conference, Philadelphia, PA, February 7-9.

Guo, Gang. 2014. "Using International Statistical Data and Excel in Teaching Introduction to International Studies." Presented at the APSA Teaching and Learning Conference, Philadelphia, PA, February 7-9.

Kilbur, H. Whitt. 2014. “Teaching the Political Science 'Brand' through Scaling Analysis." Presented at the APSA Teaching and Learning Conference, Philadelphia, PA, February 7-9.

McGuire Mary P. 2014. "Beyond Statistics: Introducing Qualitative Research to Political Science Undergraduate Students." Presented at the APSA Teaching and Learning Conference, Philadelphia, PA, February 7-9. 